\title{
The expression of malarial invasion-related molecules is affected by two different nitric oxide-based treatments
}

\author{
Li Zheng ${ }^{1}$, Hui Feng ${ }^{1}$, Di Liu ${ }^{2}$, Yan-Yan Pan ${ }^{1}$ and Ya-Ming Cao ${ }^{1}$ \\ ${ }^{1}$ Department of Immunology, College of Basic Medical Sciences, China Medical University, Heping District, Shenyang, China; \\ ${ }^{2}$ Institute of Pathology and Pathophysiology, China Medical University, Shenyang, China
}

\begin{abstract}
The host immune response to parasitic infections plays an important role in controlling multiplication of the parasite and reducing clinical symptoms and life-threatening complications. Nitric oxide (NO), an important innate immune factor and classic Th1 immune effector, may play a role in inhibiting plasmodium infection. In this study, we used two different approaches (L-Arginine [precursor of NO] and NOC5 [short-time NO donor]) to prove the roles of NO in malaria infection. We used 6-8 week-old female BALB/c mice infected with the rodent malaria Plasmodium yoelii Landau, Michel et Adam, 1968 - strain 17XL (P.y17XL) - as a model. For L-Arg treatment, mice were administered with an oral dose of $1.5 \mathrm{mg} / \mathrm{g}$ L-Arg daily for seven consecutive days prior to infection with P.y17XL. L-Arg pretreatment resulted in the decrease of the mRNA level of the apical membrane antigen 1 (AMA1) gene, which encodes a protein involved in host invasion. For NOC5 treatment, NOC5 was injected intraperitoneally into the P.y $17 \mathrm{XL}$ infected mice on day 5 post-infection or incubated in vitro with purified P.y17XL schizonts. Both in vivo and in vitro treatments with NOC5 led to down-regulation of the transcript and protein levels of invasion-related molecules (AMA1, merozoites surface protein 1 and Py235). Our results confirmed the protective role of NO in the asexual blood stage of parasitic infection, which may be partially due to reduced expression of parasite invasion molecules.
\end{abstract}

Keywords: Plasmodium yoelii, L-Arginine, NO donor, pretreatment, malaria, asexual blood stages

Human malaria, together with AIDS/HIV and tuberculosis, represents one of the three most dangerous infectious diseases of mankind (Vitoria et al. 2009). In malaria, the asexual blood stage parasite infects red blood cells (RBCs) and is responsible for all of the symptoms and complications associated with the disease (Gaur and Chitnis 2011). A large number of studies from experimental animal models to epidemiological studies have confirmed that the protective immune response against malaria involves both innate and acquired immune responses (Marsh and Kinyanjui 2006, Yazdanbakhsh and Sacks 2010, Amante et al. 2011). The establishment of an effective Th1 response during early infection has been shown to be critical in controlling multiplication of the parasite and affecting the outcome of parasite infection (Taylor-Robinson et al. 1993).

A previous study, two inbred mouse strains, DBA/2 and $\mathrm{BALB} / \mathrm{c}$, which are resistant and susceptible to blood-stage of strain 17XL of Plasmodium yoelii Landau, Michel et Adam, 1968 (P.y17XL), were used respectively (Wu et al. 2007). Th1 responses of these two rodent malaria models were compared and significant increases of $\mathrm{NO}$ production and IFN- $\gamma$ level in infected DBA/2 mice, as compared to infected BALB/c mice, was found. The endogenous IFN- $\gamma$-driven Th1 immunity is responsible for NO production (Chen et al. 2010, Zheng et al. 2010). Moreover, schizonts treated in vitro with NO donors caused a delayed infection in BALB/c mice in a time and dose-dependent manner. These data suggest that NO might affect the process of parasite invasion and thus delay the course of infection (Wang et al. 2009). We hypothesize that the production of NO might affect the adhesion between merozoites and erythrocytes.

L-Arg is the substrate of NO synthase (NOS) for the production of $\mathrm{NO}$ and therefore hypoargininemia can lead to impaired systemic NO production (Omodeo-Sale et al. 2010). In patients with severe malaria, supplementation with L-Arg has been shown to improve NO bioavailability and reverse endothelial dysfunction (Yeo et al. 2007, 2008). NOC5 (3-(2-Hydroxy-1-methylethyl-2nitrosohydrazino)-1-propanamine) is a short-time NO donor, which releases NO with a half-life of $25 \mathrm{~min}$ at $37^{\circ} \mathrm{C}$ at neutral $\mathrm{pH}$ (Takahashi et al. 2004). In the present study, we used these two different NO-based compounds to treat P.y17XL-susceptible BALB/c mice.

Invasion of erythrocytes is an essential step for malaria parasites to successfully develop in the mammalian host (Kaneko 2007). Merozoite surface protein 1 (MSP1) and 
apical membrane antigen 1 (AMA1) are essential ligands on the merozoite during the invasion process (Triglia et al. 2000, Moss et al. 2012). In addition to MSPI and AMA1, the $235 \mathrm{kDa}$ rhoptry protein $(P y 235)$ of $P$. yoelii is also a blood stage antigen. Py235 is coded by a multigene family including eleven genes. Variable expression of this protein mediates host cell adaptation and immune evasion (Iyer et al. 2006, 2007). In previous studies, PY01365 gene was found to be the dominant gene type and the transcript level of PY05054 varied depending upon the virulence of the clone. In avirulent parasite strains, the transcript level of PY05054 was high, whereas the transcript level of PY05054 was low in virulent parasite strains. Therefore, in this study, we conducted the following exploration with use of three molecules (MSP1, AMA1 and Py235) trying to evaluate the effects of NO on the interaction between the parasite and the host.

\section{MATERIALS AND METHODS}

Mice, parasites, infection and treatments

Female BALB/c mice (6-8 weeks of age) were purchased from the Centre of Zoology, Chinese Academy of Sciences. Infections by P.y $17 \mathrm{XL}$ were initiated by intraperitoneal injection of $1 \times 10^{6}$ P.y $17 \mathrm{XL}$ parasitized erythrocytes per BALB/c mouse. Parasitemia was monitored by light microscopic examination of Giemsa-stained thin blood smears. Mortality was monitored and recorded daily. All experiments were performed in compliance with the local animal ethics committee.

L-Arg (Sigma-Aldrich, St. Louis, MO, USA) was dissolved in saline before use. For animal experiments, mice in testing group were administered with oral dose of $1.5 \mathrm{mg} / \mathrm{g} \mathrm{L}$-Arg daily for seven consecutive days prior to infection with P.y17XL. Mice in the control group received D-Arg dissolved in the same volume of saline at identical time points.

NOC5 (Wako, Osaka, Japan) was dissolved in saline to a final concentration of $0,12.5,25$ or $50 \mathrm{mmol} / \mathrm{l}$. On day 5 post-infection, the mice were injected intraperitoneally with $100 \mu \mathrm{l}$ of fresh NOC5 solution. Thirty minutes later the mice were sacrificed. For in vitro experiment, NOC5 was dissolved in culture medium, and purified schizonts from untreated mice were exposed to NOC5 at a final concentration of $1.25 \mathrm{mmol} / \mathrm{l}$, $2.5 \mathrm{mmol} / 1$ or $5.0 \mathrm{mmol} / 1$ at $37^{\circ} \mathrm{C}$ for $30 \mathrm{~min}$.

\section{Enrichment of P.y17XL schizonts}

Heparinized blood was obtained via cardiac puncture from each P.y17XL-infected BALB/c mouse with $60-80 \%$ parasitemia (including untreated group, L-Arg treatment group and NOC5 in vivo treatment group) and then passed through a sterile cellulose CF11 column to remove leukocytes. The pass-through was collected until no red colour remained in the column and was then centrifuged at $3000 \mathrm{rpm}$ for $5 \mathrm{~min}$ at room temperature. The resultant pellet was resuspended in $4 \mathrm{ml}$ of PBS.

The suspension was gently laid on the top of a $50 \%$ Percoll (GE Healthcare, Munich, Germany) and centrifuged at $2000 \mathrm{rpm}$ for $20 \mathrm{~min}$ at room temperature (Hitachi himac CT6E). After centrifugation, the schizont-rich layer (approximately $95 \%$ parasitemia) was collected, $1 \times 10^{8}$ schizonts were stored in $1 \mathrm{ml}$ TRIZOL (Invitrogen, Carlsbad, CA, USA) and used for total RNA extraction. The purified schizont pellets were also stored in $-70^{\circ} \mathrm{C}$ and used for preparing parasite proteins.
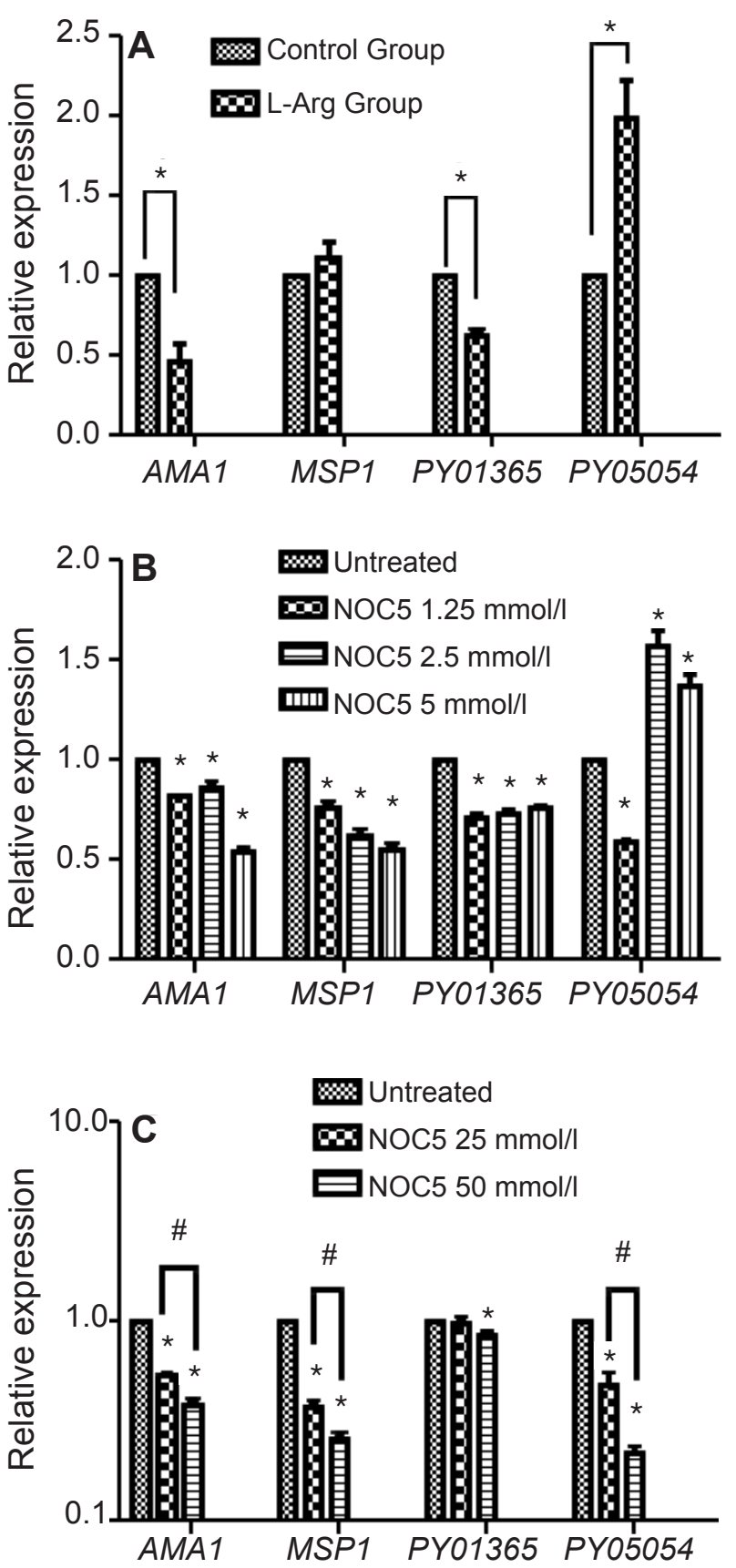

Fig. 1. Relative quantitative real-time RT-PCR of $A M A 1$, MSP1 and Py235 transcript levels with L-Arg treatment (A), NOC5 treatment in vitro $(\mathbf{B})$ and NOC5 treatment in vivo $(\mathbf{C})$. The transcript levels of AMA1, MSP1 and Py235 were detected by real-time RT-PCR using SYBR ${ }^{\circledR}$ Premix Ex Taq ${ }^{\mathrm{TM}}$ reagent kit. Abbreviations: ${ }^{*}-p<0.05$ indicates a significant difference compared to that in the control mice. For L-Arg treatment group, the control group was D-Arg treatment group; for NOC5 treatment group, the control group was untreated group; $\#-p<0.05$ indicates the comparison of transcript levels between the $25 \mathrm{mmol} / \mathrm{l} \mathrm{NOC5}$ treated group and the $50 \mathrm{mmol} / \mathrm{l}$ NOC5 treated group. The data are representative of two separate experiments. 

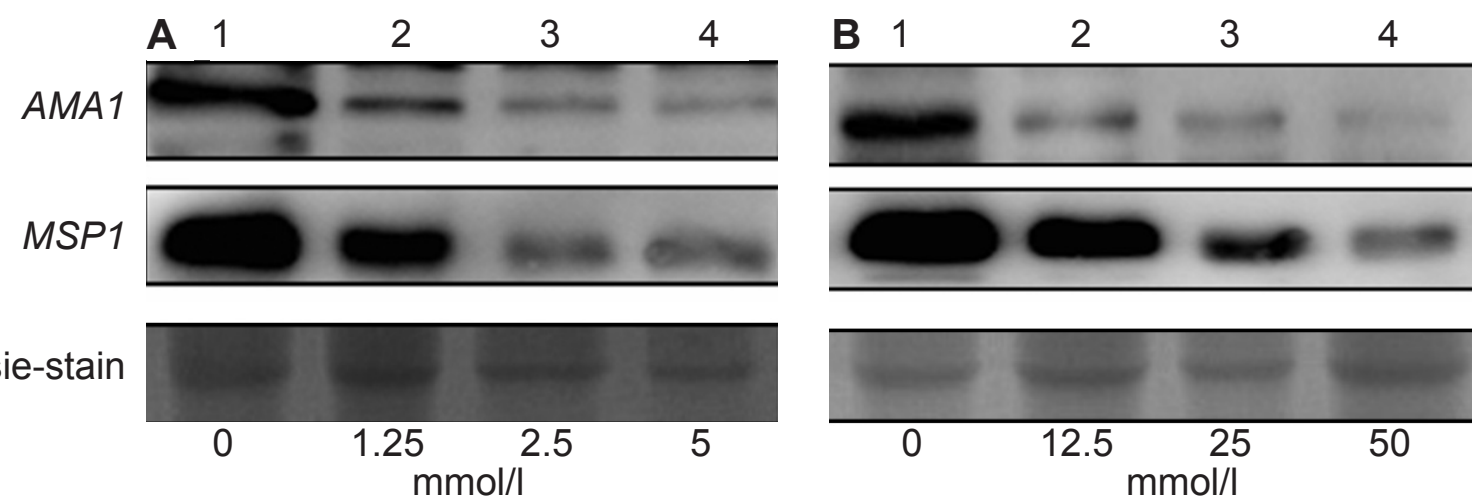

Fig. 2. Protein expression of $A M A 1$ and $M S P 1$ following treatment with NOC5 in vitro (A) and in vivo (B). The protein levels of $A M A 1$ and $M S P 1$ were detected by Western blotting using rabbit anti-MSP1 ${ }_{19}$ and rabbit anti-AMA1 as corresponding antibodies. And a Commassie-stained protein gel was used to show approximate equal loading as loading control. The data are representative of two separate experiments.

\section{RNA extraction and real-time RT-PCR}

Total RNA from schizonts was isolated using the TRIzol ${ }^{\circledR}$ reagent (Invitrogen, Carlsbad, CA, USA). The ratio of absorbance at 260/280 nm for RNA extracted from all specimens ranged from 1.8 to 2.0 . Total RNA was stored at $-70^{\circ} \mathrm{C}$. cDNA was synthesized using PrimeScript ${ }^{\mathrm{TM}}$ RT reagent kit with gDNA Eraser (Takara, Japan). Reverse transcription was performed in a $10 \mu \mathrm{l}$ reaction mixture containing PrimeScript ${ }^{\mathrm{TM}}$ buffer, PrimeScript $^{\mathrm{TM}}$ RT enzyme mix, oligo dT primer $(50 \mu \mathrm{M})$, random hexamer $(100 \mu \mathrm{M})$ and $500 \mathrm{ng}$ of total RNA.

PCR was performed with the resulting cDNA as a template and specific oligonucleotide primers. Primers used for the sequence-specific PCR were AMA1-PY01581, forward: 5'-GAAAA GGTGC ATGGT TCTGG-3', and reverse: 5'-GGGCA TTTAC CTGAT GGTAT TC-3'; MSP1-PY05748, forward: 5'-AGCAT CCCCA TCAAC AGAAG C-3' and reverse: 5'-ACTGG TTTTG CAGGT GTTGT-3'; Py235-PY01365, forward: 5'-CCATT GTACT GTCTA TTTCG TC-3' and reverse: 5'-CTCGA ATACA AAGTC GTTTA G-3'; and Py235-PY05054, forward: 5'-AATCA TTTTC TAATT GTTCG ATAG-3' and reverse: 5'-GATAA TATTT TAGAAG CATC-3'.

Quantitative PCR was carried out using SYBR® Premix Ex Taq ${ }^{\text {TM }}$ reagent kit (Takara, Japan) on AB7900 (AB, USA). After denaturation at $95^{\circ} \mathrm{C}$ for $30 \mathrm{sec}, 40$ cycles of PCR $\left(95^{\circ} \mathrm{C}\right.$ for $5 \mathrm{~s}$ and $60^{\circ} \mathrm{C}$ for $30 \mathrm{~s}$ ) were performed. Amplification of the $\beta$-actin sequence served as an internal control. The primers used for the amplification of $\beta$-actin-PY02240 were forward: 5'-TATGA AGGTA TTGGT GAAAG ATTAAC-3' and reverse: 5'-CACAT TTGTT GAAAT GTTGA CAAAG-3'.

Each experiment was performed three times independently. The average cycle threshold (CT) of the duplicate measurements was calculated. After verifying that amplification efficiencies of the target genes and $\beta$-actin were approximately equal, the $2^{-\Delta \Delta \mathrm{CT}}$ method was used to quantify the relative gene expression in either the NOC5 treatment group or the L-Arg treatment group in comparison with the control group (Livak and Schmittgen 2001). All quantitative PCR procedures, including the design of primers, validation of PCR environment and quantification methods, were performed according to the Minimum Information for Publication of Quantitative Real-Time PCR Experiments (MIQE) Guideline (Bustin et al. 2009).
Preparation of parasite protein extracts and Western blotting

Parasite protein was extracted by three times repeated freezethaw at $-80^{\circ} \mathrm{C}$ from schizont-rich pellets in PBS, $\mathrm{pH} 7.4$, containing protease inhibitors [PI; $1 \mu \mathrm{g} / \mathrm{ml}$ leupeptin, $1 \mu \mathrm{g} / \mathrm{ml}$ pepstatin A, $100 \mu \mathrm{M}$ 4-(2-aminoethyl)benzenesulfonyl fluoride hydrochloride] and $1 \mu \mathrm{mM}$ ethylenediaminetetraacetic acid (EDTA), for a final concentration of $1 \mu \mathrm{g} / 1$ used for western blotting. For each sample, $15 \mu \mathrm{g}$ of protein extracts was separated by electrophoresis on $10 \%$ polyacrylamide gel and transferred to $0.45 \mu \mathrm{m}$ PVDF membranes. Protein was detected by immunostaining with corresponding antibodies (rabbit anti-MSP $1_{19}$ and rabbit anti-AMA1, both provided by Dr. T. Tsuboi; Cell-free Science and Technology Research Center, Ehime University, Japan), followed by horseradish peroxidase (HRP)-conjugated goat antibody anti-rabbit IgG and IgM; protein bands were visualized using enhanced chemiluminescence (ECL) and detected using the BioImaging System.

\section{Statistical analysis}

Statistical analysis was performed using the Student's $t$-test. Deviation indicates significance while $p<0.05$.

\section{RESULTS}

\section{Transcription levels of invasion-related molecules}

\section{L-Arg pretreatment}

To determine the transcript level of malaria invasionrelated molecules in animals pretreated with L-Arg, realtime RT-PCR was carried out to determine the relative expression of these molecules. In comparison to the control group, the transcript levels of $A M A 1$ and Py235-PY01365 were significantly reduced $(p<0.05)$, whereas the level of Py235-PY05054 transcription increased $(p<0.05)$. The level of MSP1 transcript was not affected by L-Arg treatment in this study $(p>0.05)$ (Fig. 1A).

\section{NOC 5 treatment in vitro}

The P.y17XL mature schizonts were incubated with NOC5 for $30 \mathrm{~min}$ at a concentration of $0,1.25,2.5$ and $5.0 \mathrm{mmol} / \mathrm{l}$. In comparison to the control group, the tran- 
script level of $A M A 1$ and MSP1 decreased after NOC5 treatment in vitro $(p<0.05)$. The dominant Py235 gene type, PY01365, also decreased (compared to the $0 \mathrm{mmol} / \mathrm{l}$ group $p<0.05$ ). However, the transcript level of PY05054 decreased when the concentration of NOC5 was $1.25 \mathrm{mmol} / \mathrm{l}$, but increased at the concentrations of $2.5 \mathrm{mmol} / \mathrm{l}$ and $5.0 \mathrm{mmol} / \mathrm{l}$ (Fig. 1B).

\section{NOC 5 treatment in vivo}

For in vivo study, $100 \mu \mathrm{l}$ of NOC5 (25 and $50 \mathrm{mmol} / \mathrm{l})$ was injected into BALB/c mice infected with P.y17XL for 30 min. Transcript levels of $A M A 1$ and MSP1 decreased after NOC5 treatment, in a dose-dependent manner. For Py235 gene family, the dominant transcript PY01365 decreased in the $50 \mathrm{mmol} / 1 \mathrm{NOC} 5$ treatment group. The transcript level of PY05054 as virulence marker decreased in both NOC5 treatment groups in a dose-dependent manner (Fig. 1C).

\section{Protein levels of invasion-related molecules}

The protein expression of AMA1 and MSP1 was reduced after treatment of P.y17XL schizonts with NOC5 $(1.25,2.5$ and $5 \mathrm{mmol} / \mathrm{l})$ in vitro, compared with the untreated group ( $0 \mathrm{mmol} / \mathrm{l})$ (Fig. $2 \mathrm{~A})$, NOC5 treatment in vivo also resulted in the inhibition of protein expression of AMA1 and MSP1 (Fig. 2B). A Coomassie-stained protein gel showed the approximate equal loading which was used as loading control.

\section{DISCUSSION}

In this study, we treated the P.y17XL-susceptible BALB/c mice with two different NO-based compounds L-Arg and NOC5 to increase the host NO quantity and evaluated the effect of NO during the process of parasite invasion. We found that pretreatment with L-Arg resulted in decreased transcript levels of $A M A 1$ and a Py235 family dominant gene $P Y 01365$, whereas the transcript level of PY05054 increased. For the NOC5 treated group, both in vivo and in vitro studies showed reduced transcript and protein levels of MSP1 and AMA1 molecules. Moreover, this inhibition was dose-dependent. The transcript level of PY05054 increased in the in vitro treatment group, whereas decreased in the in vivo group.

NO, as a low molecular weight and highly diffusible molecule, is produced by NADPH oxidase during the 'oxidative burst' (Fang 2004). Recently, several studies have focused on the apoptotic mechanism via NO induction (Bonavida and Baritaki 2011, Herbst et al. 2011). The former authors found that the tumor cell was more sensitive in the process of apoptosis through NO-induced NF- $\kappa$ B/Snail/YY1/RKIP circuitry when following treatment of tumor cells with NO donors (DETA NONOate) (Bonavida and Baritaki 2011).

NO has also been shown to play an antimicrobial role against infection by intracellular microbes, such as myco- bacteria, by the induction of host cell apoptosis. Moreover, IFN- $\gamma$-induced apoptosis in mycobacteria-infected macrophages was found to be strictly dependent on NO (Herbst et al. 2011). In the present study, the levels of transcript and protein of several parasite invasion-related molecules (AMA1, MSP1 and Py235) were reduced after treatment with NOC5. We hypothesize that this inhibition might be induced by NO-dependent apoptosis.

Interestingly, a virulence gene, PY05054, from the Py235 family responded differently to NOC5 and L-Arg treatment (Iyer et al. 2006, 2007). The transcript level of PY05054 increased in the L-Arg pretreatment and NOC5 in vitro treatment group, but decreased in the NOC5 in vivo treatment group. For the in vitro NOC5 treatment, NO may be directly toxic and therefore reduce the viability of the parasites. This would also explain the phenomenon observed in a previous study of the present authors, in which schizonts treated in vitro with $\mathrm{NO}$ donor caused a delayed infection in BALB/c mice in a time and dosedependent manner (Wang et al. 2009).

These data also support the result that pretreatment with L-Arg improves the survival of mice during infection with P.y17XL (Zhu et al. 2012). However, the virulence of the parasites was enhanced when the infected mice were treated with NOC5 in vivo. This alteration might be induced by the pressure from NO and the parasites might use the host environment and change their phenotype.

However, the mechanism by which the parasite evaded the pressure of NO is still unclear. NO and Reactive oxygen species (ROS) are considered as early step for effective host immune responses to invasive microorganisms. Therefore, nitrosative stress is an ongoing challenge that most organisms have to contend with. However, the contribution of cellular metabolism to fending off nitrosative stress is poorly understood in eukaryotic microorganisms, particularly for Plasmodium. Further investigation is necessary to elucidate the mechanism of this stress.

Taken together, invasion of erythrocytes is an essential step for malaria parasites to successfully develop in a mammalian host and the present data suggest that the expression of parasite invasion-related molecules (AMAI and $M S P 1$ ) is down-regulated by NO. The virulence of the parasite might be attenuated by treatment with an NO donor in vitro, but strengthened by treatment with an NO donor in vivo. These results suggest that NO, as an important innate immune factor and classic Th1 immune effector, might play a protective role against plasmodium infection by affecting the course of parasite invasion. This inhibition might be related to the lower expression of parasite invasion-related ligand molecules, such as $A M A 1$ and MSP1.

Acknowledgements. We are grateful to Dr. L. Cui (Department of Entomology, Pennsylvania State University, University Park, Pennsylvania, PA,USA) for helpful suggestions. This work was supported by grants from the National Natural Science Foundation of China (30800962). 
Amante F.H., Engwerda C.R., Good M.F. 2011: Experimental asexual blood stage malaria immunity. In: J.E. Coligan, B.E. Bierer, D.H. Margulies, E.M. Shevach and W. Strober (Eds.), Curr. Protoc. Immunol. 93: 19.4.1-19.4.26

Bonavida B., BARITAKI S. 2011: Dual role of NO donors in the reversal of tumor cell resistance and EMT: downregulation of the NF-kappaB/Snail/YY1/RKIP circuitry. Nitric Oxide 24: 1-7.

Bustin S.A., Benes V., Garson J.A., Hellemans J., Huggett J., Kubista M., Mueller R., Nolan T., Pfaffl M.W., ShipLey G.L., Vandesompele J., Wittwer C.T. 2009: The MIQE guidelines: minimum information for publication of quantitative real-time PCR experiments. Clin. Chem. 55: 611-622.

Chen G., Feng H., Liu J., Qi Z.M., Wu Y., Guo S.Y., Li D.M., WANG J.C., CAO Y.M. 2010: Characterization of immune responses to single or mixed infections with P. yoelii 17XL and $P$. chabaudi AS in different strains of mice. Parasitol. Int. 59: 400-406.

FANG F.C. 2004: Antimicrobial reactive oxygen and nitrogen species: concepts and controversies. Nat. Rev. Microbiol. 2: 820832.

Gaur D., Chitnis C.E. 2011: Molecular interactions and signaling mechanisms during erythrocyte invasion by malaria parasites. Curr. Opin. Microbiol. 14: 422-428.

Herbst S., Schaible U.E., Schneider B.E. 2011: Interferon gamma activated macrophages kill mycobacteria by nitric oxide induced apoptosis. PLoS ONE 6: e19105.

Iyer J.K., Amaladoss A., Genesan S., Preiser P.R. 2007: Variable expression of the $235 \mathrm{kDa}$ rhoptry protein of Plasmodium yoelii mediate host cell adaptation and immune evasion. Mol. Microbiol. 65: 333-346.

Iyer J.K., Fuller K., Preiser P.R. 2006: Differences in the copy number of the py 235 gene family in virulent and avirulent lines of Plasmodium yoelii. Mol. Biochem. Parasitol. 150: 186-191.

KANEKO O. 2007: Erythrocyte invasion: vocabulary and grammar of the Plasmodium rhoptry. Parasitol. Int. 56: 255-262.

Livak K.J., Schmittgen T.D. 2001: Analysis of relative gene expression data using real-time quantitative PCR and the 2(-Delta Delta C(T)) method. Methods 25: 402-408.

Marsh K., Kinyanjui S. 2006: Immune effector mechanisms in malaria. Parasite Immunol. 28: 51-60.

Moss D.K., Remarque E.J., Faber B.W., Cavanagh D.R., Arnot D.E., Thomas A.W., Holder A.A. 2012: Plasmodium falciparum 19-kilodalton merozoite surface protein 1 (MSP1)specific antibodies that interfere with parasite growth in vitro can inhibit MSP1 processing, merozoite invasion, and intracellular parasite development. Infect. Immun. 80: 1280-1287.

Omodeo-Sale F., Cortelezzi L., Vommaro Z., Scaccabarozzi D., Dondor P A.M. 2010: Dysregulation of L-arginine metabo-

Received 28 September 2012 lism and bioavailability associated to free plasma heme. Am. J. Physiol. Cell Physiol. 299: C148-154.

Takahashi K., Numata N., Kinoshita N., Utoguchi N., Mayumi T., Mizuno N. 2004: Characterization of the influence of nitric oxide donors on intestinal absorption of macromolecules. Int. J. Pharm. 286: 89-97.

Taylor-Robinson A.W., Phillips R.S., Severn A., Moncada S., Liew F.Y. 1993: The role of Th1 and Th2 cells in a rodent malaria infection. Science 260: 1931-1934.

Triglia T., Healer J., Caruana S.R., Hodder A.N., Anders R.F., Crabb B.S., Cowman A.F. 2000: Apical membrane antigen 1 plays a central role in erythrocyte invasion by Plasmodium species. Mol. Microbiol. 38: 706-718.

Vitoria M., Granich R., Gilks C.F., Gunneberg C., Hosseini M., Were W., Raviglione M., De Cock K.M. 2009: The global fight against HIV/AIDS, tuberculosis, and malaria: current status and future perspectives. Am. J. Clin. Pathol. 131: 844-848.

Wang Q., Liu Y.J., Liu J., Chen G., Zheng W., Wang J.C., CAOY.M. 2009: Plasmodium yoelii: assessment of production and role of nitric oxide during the early stages of infection in susceptible and resistant mice. Exp. Parasitol. 121: 268-273.

Wu Y., Wang Q.H., Zheng L., Feng H., Liu J., Ma S.H., CaO Y.M. 2007: Plasmodium yoelii: distinct CD4(+)CD25(+) regulatory $\mathrm{T}$ cell responses during the early stages of infection in susceptible and resistant mice. Exp. Parasitol. 115: 301-304.

YAZDANBAKhsh M., SACKs D.L. 2010: Why does immunity to parasites take so long to develop? Nat. Rev. Immunol. 10: 80-81.

Yeo T.W., Lampah D.A., Gitawati R., Tuitra E., Kenangalem E., Granger D.L., Weinberg J.B., Lopansri B.K., Price R.N., Celermajer D.S., Duffull S.B., Anstey N.M. 2008: Safety profile of L-arginine infusion in moderately severe falciparum malaria. PLoS ONE 3: e2347.

Yeo T.W., Lampah D.A., Gitawati R., Tutra E., Kenangalem E., McNeil Y.R., Darcy C.J., Granger D.L., Weinberg J.B., Lopansri B.K., Price R.N., Duffull S.B., Celermajer D.S., Anstey N.M. 2007: Impaired nitric oxide bioavailability and L-arginine reversible endothelial dysfunction in adults with falciparum malaria. J. Exp. Med. 204: 2693-2704.

Zheng W., Wang Q.H., Liu Y.J., Liu J., Feng H., Wu J.J., Cao Y.M. 2010: Distinct host-related dendritic cell responses during the early stage of Plasmodium yoelii infection in susceptible and resistant mice. Parasite Immunol. 32: 324-334.

Zhu X., Pan Y., Li Y., Cui L., CaO Y. 2012: Supplement of L-Arg improves protective immunity during early-stage Plasmodium yoelii 17XL infection. Parasite Immunol. 34: 412-420.

Accepted 4 February 2013 